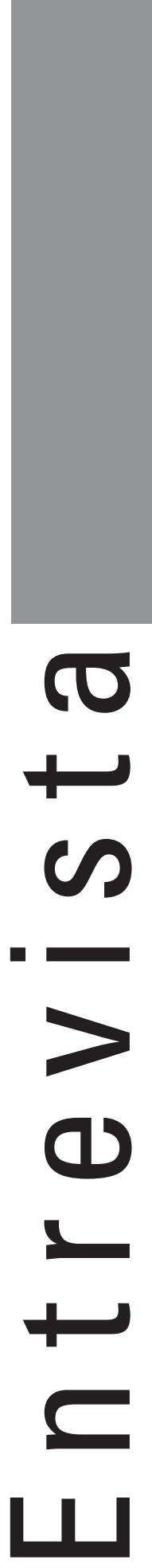





\title{
Planos Plurianuais: desafios da gestão voltada para resultados
}

\author{
Entrevistada: Sulamita de Aquino Porto Mello e Cunha \\ sulamita@seplango.gov.br
}

Entrevista concedida a Tathiana R. Salgado em 23 de Maio de 2009

A partir do final da década 1990, por meio da elaboração dos Planos Plurianuais (PPA), um novo modelo de intervenção regional baseado nas diretrizes do planejamento estratégico passou a integrar a agenda de preocupação do Governo do estado Goiás. Esses planos são instrumentos de planejamento das ações de governo em médio prazo, normalmente quatro anos, que estabelecem diretrizes, objetivos e metas das administrações públicas para as despesas de capital e outras delas decorrentes, devem apresentar com clareza os resultados pretendidos pelo governo que o elabora.

Embora previsto nas Constituições federais e estaduais desde final da década de 1980, os dois primeiros PPA’s de Goiás só ocorreram entre 2000 e 2007, após a eleição de Marconi Perillo para governador do estado. O primeiro plano foi denominado de Goiás para o século XXI - PPA 2000/2003 e o segundo denominado de Goiás para o século XXI - avançar mais - PPA 2004/2007. O objetivo central do conjunto de programas contidos nos PPA's e protagonizado pela SEPLAN - GO (Secretaria de Planejamento e Desenvolvimento de Goiás) e pela AGDR (Agência Goiana de Desenvolvimento Regional), foi assegurar o desenvolvimento da competitividade da economia goiana e a consolidação de sua integração aos mercados nacionais e internacionais.

Em entrevista concedida ao Boletim Goiano de Geografia, Sulamita de Aquino Porto Mello e Cunha, Superintendente de planejamento e desenvolvimento da SEPLAN fala sobre o novo modelo de planejamento adotado pelo Governo do estado de Goiás a partir de 1999.

\section{BGG: 0 que os PPAs, como marca da gestão pública a partir de 1999, conferem de novo na relação governo-sociedade?}

Sulamita: Uma pergunta muito interessante. A partir da década de 1990, com o Governo Fernando Henrique, foi-se introduzindo, no estado de Goiás, uma gestão voltada para resultados. Foi a introdução desse modelo de gestão pública que mudou todo o perfil. Foi o divisor de água. Por quê? Porque até então não 
se trabalhava a gestão em forma de programas. As ações do governo eram muito dispersas, não davam visibilidade. A gestão voltada para resultados tem como elemento integrador o programa. Este programa é o elemento integrador do PPA (Plano Plurianual),com a LDO (Lei de Diretrizes Orçamentárias) e a LOA (Lei Orçamentária Anual). Então, tudo decorre em termo de legislação orçamentária e de planejamento. O programa tem como base o PPA, que é uma gestão voltada para resultados, onde foi possível ter transparência em nível de gestão pública, porque se você aglutina as ações em forma de programas, a transparência é muito maior. Outra coisa foi a responsabilização. Cada programa e ação do governo tem um responsável. Isso também foi um grande avanço, pois você tem a pessoa que sabe quem é o responsável por determinados programas. Desse modo, ele não fica solto no âmbito da gestão pública, tem-se a transparência e, principalmente, esta responsabilização que são os dois elementos básicos e inovadores dessa gestão. Tudo é voltado para resultados, e o principal beneficiador é a sociedade. Tudo o que é feito no PPA é medido, se é uma ação voltada para resultados, eu tenho que medir. Então eu considero o PPA um grande divisor de águas da gestão pública.

\section{BGG: $E$ as prefeituras, como participam?}

Sulamita: Esse modelo de gestão voltado para resultados foi introduzido na época do Governo Fernando Henrique e ele é todo gerenciado no Ministério de Planejamento, Orçamento e Gestão que tem uma secretária própria de planejamento estratégico que volta todas suas ações para isso. Então, toda normatização com relação ao PPA é feita através do Ministério do Planejamento. Não que todos os estados tenham que seguir aquele modelo. $\mathrm{O}$ estado de Goiás, posso te afirmar, foi um dos cinco primeiros a elaborar o PPA. Nós fizemos o primeiro PPA de 1999 a 2003, juntamente com o Governo Federal. Nós aprendemos todos juntos. Não foi fácil, pois era um modelo de planejamento totalmente novo. Apesar de previsto desde 1988, o primeiro PPA de Goiás só foi elaborado em 1999. Com relação aos municípios, a lei os obriga a fazer, mas a gestão dos municípios fica muito dependente de consultores que façam isso. A grande maioria das prefeituras, principalmente as menores, não possui técnicos eficientemente preparados para elaborar um planejamento como esse.

\section{BGG: Mas as prefeituras participam na elaboração do PPA estadual?}

Sulamita: Não, a prefeitura não. Veja bem, eles não participam diretamente, mas participam indiretamente através de audiências públicas. Na medida 
em que o PPA é elaborado, é feita a consulta à sociedade, e essa consulta é feita através dos municípios. Temos 246 municípios, mas não dá para ir a todos. Faz-se uma regionalização de todo o estado de Goiás para efeito de auditoria pública do PPA. Então, escolhe-se, geralmente, entre 10 e 12 regionais, no máximo, e escolhe-se um município sede. Geralmente é escolhido um município de grande porte, onde são convidados todos aqueles municípios circunvizinhos para estarem participando da audiência pública. Assim, o município indiretamente participa. Nesse momento, o município dá sua opinião, e essa opinião ou sugestão é passada para a secretaria, por exemplo, se um município faz uma sugestão na área de saúde. A Secretaria de Planejamento encaminha aquela sugestão para a Secretaria de Saúde. Se a sugestão é na área de educação, a Secretaria de Planejamento encaminha essa sugestão para a Secretaria de Educação, que volta de novo para a Secretaria de Planejamento e faz a compatibilização em termos de ajustar aquela demanda com as ações do PPA.

\section{BGG: Como os demais atores governamentais, especialmente os municípios, incorporaram as mudanças que são produto do PPAs?}

Sulamita: Receberam bem. Mas como eu te falei, não podemos generalizar. Temos municípios muito pequenos, com uma deficiência técnica muito grande. Mas mesmo assim, o governo federal, se eu não me engano, no PPA passado, fez uma conferência para a qual foram convidados todos os prefeitos e os auxiliares. Eu, particularmente, acho isso muito pouco. Acho que no estado falta uma Secretaria de Articulação, diretamente ligada aos municípios, para fazer a capacitação técnica a nível gerencial. Do meu ponto de vista, ela ainda é deficiente. Não estou falando pelo governo.

\section{BGG: Como são elaborados os programas contidos nos PPAs?}

Sulamita: A secretaria de planejamento gerencia toda a ação do PPA. Vamos dizer, ela coordena. Quem sabe de saúde? A Secretaria de Saúde. Quem sabe de educação? A Secretaria de Educação. Então, como surgem esses programas? Sempre tem uma orientação. O programa surge a partir de um problema da sociedade que o Governo se propõe a resolver a partir de uma demanda da sociedade, ou pode surgir também um programa de governo a partir de uma potencialidade. Não é um problema, mas uma potencialidade. Por exemplo, o estado de Goiás é muito rico em nível de turismo/ecoturismo, então faz-se um programa para desenvolver aquela potencialidade. São duas condições que eu considero as mais básicas. A partir da demanda de um pro- 
blema, por exemplo, existe alta mortalidade infantil, então é uma demanda da sociedade que e o governo deve fazer um programa para redução daquela mortalidade. Ou no caso de um potencial, como o ecoturismo e a mineração, nos quais o estado de Goiás é rico, cabe ao governo fazer um programa para cada vez mais incentivar o desenvolvimento dessa potencialidade.

\section{BGG: As secretarias ficam então responsáveis por elaborar esses programas?}

Sulamita: Sim, mas não só as secretarias. Nisso também houve uma grande mudança. Quer dizer, não é um programa da Secretaria de Saúde, é um programa de governo. Quando nós falamos em um programa de governo, as secretarias não podem resolver todas as questões só olhando para elas mesmas. Então, a orientação que damos em várias reuniões é que as ações sejam integradas, ou seja, que a Secretaria de Saúde junto com a Secretaria de Educação e a Secretaria de Segurança Pública, sendo órgãos afins, possam se integrar. Acho que isso é o grande avanço que vai ter na gestão e no PPA, é o que estamos tentando, ou seja, até onde a ação de determinada secretaria começa e acaba, e onde o outro órgão pode começar outra ação para dar prosseguimento. Por exemplo, com relação às drogas na escola, a Secretaria de Educação tem que se preocupar com os alunos que estão envolvidos com drogas, alertá-los sobre o consumo de drogas e sobre como prevenir o consumo de entorpecentes, o que ela já faz, buscando apoio junto à Secretária de Segurança Pública, por exemplo. E a Secretaria de Segurança Pública exercem várias ações que se integram com outros setores. Por exemplo, hoje, os detentos fazem várias bolas de futebol, que depois são distribuídas às varias associações de esporte, solicitadas pela AGEL (Agência Goiana de Esporte e Lazer), então, quanto mais as ações forem integradas, mais os resultados serão melhores, e isso é nosso grande esforço.

\section{BGG: Lendo os PPAs, é possível notar, por exemplo, uma diferença metodológica na regionalização do primeiro (2000-2003) para o segundo (2004-2005). 0 que justificou essa mudança?}

Sulamita: Nós passamos por lições aprendidas, e tudo o que fazemos é um processo que vai melhorando. Como eu disse a você, o primeiro PPA que fizemos em Goiás foi junto com o Governo Federal. Então, quer dizer que estávamos em um processo de aprendizagem, um processo metodológico. Já no segundo PPA, nós já tínhamos mais segurança em falar. Não fica mais transparente, e "força" as pessoas planejarem melhor se for regionalizado? Por exemplo, se eu falo em região Nordeste goiano, o que ela vai precisar 
em termos de promoção social é muito maior, muito diferente do Sul goiano. É uma região muito mais carente, então, quando se vai investir, existe uma diferenciação dos investimentos, dependendo da região. Você, como geógrafa, deve saber disso. No primeiro PPA, não tínhamos essa regionalização, primeiro que nós não tínhamos a esperteza necessária para pensar a regionalização naquela época, estávamos procurando acertar, ver o que era um programa, ver o que era uma ação, como seria a metodologia do PPA. Já no segundo, já tínhamos mais, e agora melhoramos. Qual a diferença entre o segundo e esse terceiro? Nós definimos a região Metropolitana de Goiânia, o Nordeste goiano, o Norte goiano e o Entorno de Brasília. O resto, nós colocávamos a regionalizar. Quando foi nesse último PPA, nós recebemos a consultoria de geógrafos, como: Valter Casseti, professora Celene, professor Teixeira Neto, que é um guru na área de vocês, entre outros. Tivemos a consultoria da Universidade Federal de Goiás para fazer essa regionalização.

\section{BGG: Como ocorre a avaliação dos impactos das ações?}

Sulamita: O planejamento segue o ciclo P - D - C - A, ou seja, eu planejo, eu desenvolvo, eu controlo e eu avalio. O planejamento ocorre quando eu estou elaborando os instrumentos no desenvolvimento, são as ações que estão sendo executadas. O controle é todo o monitoramento. E na avaliação, estou avaliando aquilo que estou monitorando. Hoje, como é feita essa avaliação? Essa avaliação é feita, principalmente, através da GECONI (Gerência de Controle Interno), que é um órgão que fiscaliza o que é executado pelo governo. Eles têm toda uma metodologia para fazer a avaliação dos resultados. A Secretaria do Planejamento vai realizar hoje a segunda rodada de reuniões em que nós vamos avaliar, inovando esse processo de avaliação, cada programa, cada ação, para chegar a uma avaliação do órgão, para chegar a uma avaliação do governo. Começamos dia 09 e até o fim do ano vamos concluir.

\section{BGG: 0 primeiro PPA apresenta 125 projetos, distribuídos em 20 setores econômicos. No segundo PPA são 90, distribuídos em 16 setores econômicos. 0 que determina a quantidade de projetos, a necessidade ou a demanda?}

Sulamita: É a demanda, porque jamais podemos chegar à Secretária de Saúde e dizer que eles só vão ter dois programas. Quem sabe quantos programas vão ter, são eles. É muito em função da demanda. Nesse segundo teve uma redução de programas devido ao processo de amadurecimento dentro do órgão, pois no começo foi se fazendo programa, programa e, de repente, na avaliação notava-se similaridade entre objetivos de diferentes programas, 
então podia se fazer a aglutinação. É um processo mesmo de aprendizagem que levou as pessoas a terem mais consciência daquilo que elas estavam propondo, de acordo com aquelas questões e necessidades.

\section{BGG: Tem alguma relação com o orçamento?}

Sulamita: Não. Essa é uma pergunta interessante. No começo, quando nós recebemos o primeiro PPA, tinha uma série de confusões, nas quais as pessoas achavam que quanto mais ações elas tinham, mais valores financeiros e mais recursos orçamentários teriam para elas. Por mais que nós falávamos que não era assim, tentamos reduzir, mas ainda tínhamos muitas ações, e se você observar, o segundo tem bem menos ações, porque não é o número de ações que assegura o orçamento, o recurso. Quanto mais ação, mais difícil é a execução, porque para cada ação, eu tenho que ter um empenho diferente. Se eu aloco 50 mil na ação A e coloco 50 mil na ação B, elas têm mais ou menos os mesmos objetivos. Eu teria que fazer dois empenhos diferentes. Se eu aglutino essas duas ações, elas têm 100 mil, e o processo de execução orçamentária fica muito mais fácil e menos burocrático.

\section{BGG: Observando a distribuição dos projetos nas regiões, notamos determinados perfis de investimentos (como exemplo, o programa PRODUZIR, ou construção de lagos, distribuição de kits sanitários). A que se devem esses perfis?}

Sulamita: Perfil de investimentos, como eu te disse, ele vai de acordo com a necessidade. Esse kit vai ser distribuído na região onde há maior necessidade. Onde se tem um potencial mais produtivo, as ações vão ser voltadas para esse setor produtivo. E o retorno, o custo benefício que o governo vai ter, por exemplo, é onde eu tenho uma terra mais fértil, pois vou ter um retorno mais rápido, não que o outro fique esquecido. Se você for observar a distribuição de recursos do governo federal para a ciência e para a tecnologia, você nota um padrão Sul/Sudeste, por quê? Porque já tem toda uma infraestrutura que dará mais retorno. Mas essa concepção tem que ser mudada, porque se você ficar sempre dessa forma, não dá oportunidade para todos, mas hoje ainda é feito dessa forma.

\section{BGG: Quais os principais desafios dos PPAs, especialmente em relação ao Norte, Nordeste e Entorno do Distrito Federal?}

Sulamita: Mais investimentos, principalmente no setor produtivo. O Entorno de Brasília é diferenciado das demais regiões pela questão da violência e da população que teve um crescimento vertiginoso. O Entorno de Brasília é formado por cidades onde as pessoas não têm identidade própria, principal- 
mente na área mais conurbada. São cidades dormitório onde há uma grande rotatividade. É muito difícil trabalhar ali, principalmente para a geração de empregos e de renda. O estado de Goiás, muitas vezes, é considerado um laboratório. Ele treina professores, treina médicos, serve de laboratório, pois as pessoas se deslocam todas para Brasília. Por quê? Não temos condições de competir com o Distrito Federal em termos de remuneração. Então, o grande desafio para essas regiões é desenvolver programas para geração de emprego e renda, e desenvolver o potencial para o ecoturismo da região nordeste.

\section{BGG: Qual é a função da AGDR e da SEPLAN?}

Sulamita: Você deve ter visto no PPA passado que existiam atribuições semelhantes na área do desenvolvimento regional aqui para SEPLAN e para AGDR. Mas você já vai ver agora no último PPA, nessa reforma administrativa, que toda a parte referente ao desenvolvimento regional não tem nada mais a ver com a SEPLAN, ela ficou toda com a AGDR. É ela que dita toda a política em termos de desenvolvimento regional do estado. Eu acho realmente que ficando aqui na SEPLAN e na AGDR ficava uma duplicidade de comando, às vezes, uma sobreposição de ações, o que não é bom. Acho que como está agora é bom, um órgão só e que dita o que é o desenvolvimento regional.

\section{BGG: 0 que houve de avanço em termos de correção dos desequilíbrios regionais de desenvolvimento?}

Sulamita: Temos que caminhar bastante. As regiões Norte, Nordeste e Entorno são regiões que têm que caminhar muito para diminuir o desequilíbrio. Se você olhar os dados de 10 anos atrás, o desequilíbrio era bem maior, então, houve um avanço, mas ainda temos que avançar bastante. 
